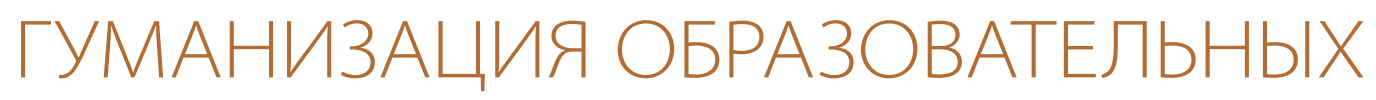
ИНТЕРНЕТ-ТЕХНОЛОГИЙ

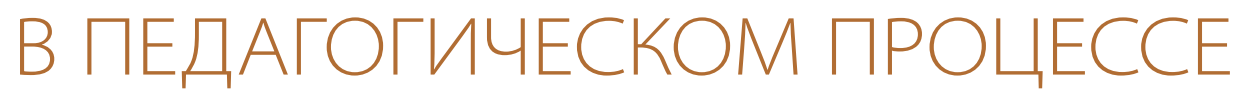

\title{
HUMANIZATION OF EDUCATIONAL INTERNET TECHNOLOGIES IN THE PEDAGOGICAL PROCESS
}

\section{Дерюга Вардан Евгеньевич}

Доцент кафедры педагогики, Мордовский государственный педагогический институт имени М. Е. Евсевьева, г. Саранск, кандидат педагогических наук

E-mail: vardmob@yandex.ru

Аннотация. Анализируется проблема влияния цифровых технологий на развитие традиционного и гуманистического образования. Процесс цифровизации рассматривается как этап смены индустриально-образовательной системы новой информационно-цифровой системой образования. Обосновываются проблемы дегуманизации образования и предлагаются пути их преодоления.

\section{Ключевые слова: гуманизм, культурная} традиция, образование, индустриальнообразовательная система, информационноцифровая система, парадигма, технологизм, духовность, ценности.

\section{Deryuga Vardan E.}

Assistant Professor at the Department of Pedagogy, Mordovia M. E. Evsevyev State Pedagogical Institute, Saransk, PhD in Education

E-mail:vardmob@yandex.ru

Abstract. The issue of the influence of digital technologies on the development of traditional and humanistic education is analyzed. The digitalization process is considered as a stage in the replacement of the industrial-educational system with a new information-digital education system. The problems of dehumanization of education are substantiated and ways to overcome them are proposed.

Keywords: humanism, cultural tradition, education, industrial-educational system, digital information system, paradigm, technologism, spirituality, values. 
Россия, как и большинство развитых стран, вступила в технологическую информационную эпоху, которую часто называют постиндустриальной. Жизнь становится все более «оцифрованной», роботы заменяют человека во многих видах деятельности, огромные объемы информации обрабатываются мгновенно, коммуникация посредством социальных сетей и мессенджеров стала быстрой и глобальной, виртуальное пространство начинает заменять реальность, широко применяется удаленное управление различными системами (общественными, техническими и т. д.). Изменения стали постоянными и происходят в «режиме онлайн», а ценность материальных ресурсов все более дополняется ценностью информационных данных (“big data”).

Цифровая реальность вторглась в том числе в систему образования, которая технологизируется у нас на глазах. Образовательные технологии становятся все более цифровыми, виртуальными, дистанщионными, облачными, связанными с интернет-ресурсами. Например, в Подмосковье в качестве эксперимента компьютеры частично будут проверять домашние задания детей1, развитие получают электронные образовательные порталы (www.mos.ru, https:// resh.edu.ru, https://education.yandex.ru, и др.), системы онлайн-курсов (www.lektorium.tv, https://www.coursera.org, https://stepik.org и др.). В ближайших планах создание федеральной платформы цифровой образовательной среды (ЦОС), куда могут войти данные о страницах в соцсетях учеников, их родителей и учителей. ЕГЭ стал полностью технологически обеспечен на всех этапах его проведения и проверки. Вопросы практического использования цифровых технологий рассматриваются как педагогами-практиками, так и научным педагогическим сообществом [1-3]. По мере стремительного развития технологий нейросети в ближайшие 5-10 лет будут учить детей и, возможно, сделают это не менее качественно, чем живой учитель. В недалеком будущем весь образовательный контент будет оцифрован (это уже происходит сейчас), систематизирован по предметам, возрасту детей и образовательным направлениям и представлен в качестве единой платформы с соответствующими методическими онлайнрешениями (лекциями, заданиями, рабочими тетрадями и оценочными средствами). Шаг за шагом ученика будет вести виртуальный помощник образовательной «онлайн-игры», ставя ему цифровые баллы для получения итогового «аттестата».

Процесс цифровизации и технологизации массового образования неизбежен. Мы вступили в постиндустриальную цифровую (информационно-технологическую) эпоху. Все аспекты жизни, связанные с информационными ресурсами, в том числе и система образования, будут стремительно меняться, отвечая на вызов новым требованиям жизни.

Последние подобные глобальные изменения системы образования происходили в период индустриализации. Тогда в XVIII-XIX вв. в условиях роста промышленности, банковской сферы, в условиях урбанизации и становления национальных государств системы образования приобрели современные черты, отвечающие требованиям индустриального уклада. Ведущей формой организации образовательного процесса стала классно-урочная система. Еще раныше Ян Амос Коменский, а позже Иоганн Генрих Песталоцци, Адольф

1 https://zen.yandex.ru/media/young_teacher/v-shkolah-podmoskovia-domashnie-zadaniia-budetproveriat-kompiuter-5cf73b1434ace300afb30321 
Дистервег, Иоганн Фридрих Гербарт, Константин Дмитриевич Ушинский - эти и многие другие неизвестные нам педагоги внесли свой великий вклад в развитие теории педагогики и практики классно-урочной системы своих стран и всего мира.

Классно-урочная система была порождением индустриальной организации производства: «Сырье преобразуется в товар в результате прохождения через конкретную последовательность технологических стадий, где тестирование служит своеобразным пропуском при переходе от стадии к стадии. Массовое образование также представляет собой ряд этапов - от начальной до средней школы и далее к высшей. Учащиеся, как правило, проходят через систему группами, состав которых обусловлен исключительно датой рождения» [4]. Линейная технология производства была перенесена в систему образования. Все ученики разбиваются по классам в соответствии с возрастом, а иногда и способностями. Уроки проходят в строго отведенное время (30-45 мин) с малыми и большими перерывами. Каждое занятие посвящено определенному предмету и теме, все они распределены по плану и объединены в болышие циклы с итоговой проверкой знаний. И как по конвейеру проходит будущий продукт, так и дети ступают с первого класса до окончания школы.

Классно-урочную систему можно назвать индустриально-образовательной (индустриальной формой организации образования). Она сделала массовым традиционное образование, которое получило развитие еще в период становления аграрного образа жизни (примерно 12000 лет назад). Его цель - передача культурной традиции из поколения в поколение. Это диктовалось постоянным созданием и соответственно накоплением Человеком материальных и духовных объектов культуры, которые «требовали» ухода за собой и передачи последующим поколениям. Так на протяжении многих тысяч лет человечеством был накоплен огромный пласт разнообразной культуры, а образование стало традицией сохранять и передавать эту культуру из прошлого в будущее.

Период индустриализации сделал массовым традиционное образование, а классноурочная система прижилась как основная форма его организации. Однако важным является тот факт, что в период развития наук, искусств и производств новые знания о Человеке сделали автономной идею гуманизма и внесли новую цель в образовательный процесс - раскрытие Личностью своего потенциала и реализацию Человеком своего «Я» на благо общества, государства и самого себя.

Таким образом, массовая индустриально-образовательная классно-урочная система с периода своего становления имела две глобальные цели образования: передачу культурной традиции (знаний, умений, навыков, опыта) из поколения в поколение и, с другой стороны, развитие свободной критически мыслящей Личности, способной к творческой самореализации.

Представленные традиционная и гуманистическая цели существовали бок о бок, соперничая и дополняя друг друга вплоть до XXI в., пока обе не столкнулись с единым вызовом - информационными технологиями. Они (Интернет, системы коммуникации, мобильные приложения и т. д.) «бьют» одновременно по двум целям, разрушая традиционные и гуманистические подходы в системе образования. На наших глазах индустриально-образовательная система сдает позиции, а на смену ей приходит информационно-образовательная парадигма (информационно-цифровая система образования). 


\section{Почему и как это происходит?}

Благодаря развитию информационных технологий и виртуального пространства появилась возможность сохранять, обрабатывать и передавать на большие расстояния неограниченному количеству пользователей огромные объемы информации. Это меняет педагогический процесс со всех трех сторон: административной, воспитательной и образовательной.

Со стороны организации педагогического процесса (административной) процесс информационной технологизации привел к возможностям автоматизации и контроля всей образовательной системы. На практике это выражается в введении систем онлайн-обучения (контроль за всеми этапами прохождения), мониторинга (например, ЕГЭ), выставления онлайн-отметок (электронный дневник), проверок посещаемости (контроль по магнитным картам на входе).

Нет причин думать, что возникшие завтра технологии не будут применены в системе образования, поскольку они прямо «искушают» желанием автоматизировать педагогический процесс, сделать его технически совершенным, словно идеальный механизм, который никогда не дает сбоев и тогда гарантирует высочайший результат. Да, результатом усиления технологической составляющей стала ориентация в первую очередь на контроль процессов и результатов.

Это, конечно, дегуманизирует процесс образования, а его участников (педагогических работников, учащихся и родителей) заставляет приспосабливаться к вновь возникшим условиям и требованиям. Хотя, по логике вещей, технические возможности должны не просто помогать в организации педагогического процесса, они должны стать средством для помощи Человеку в решении образовательных задач. А на деле получается, что ученик, учитель, родители становятся средством появляющихся новых технических инноваций и решений. Так идея гуманизма подменяется технократической идеологией.

На процесс собственно образования (обучение, окультуривание Человека) технологии также оказывают мощнейшее влияние. В первую очередь, это проявляется в разрушении традиций индустриально-образовательной системы. В ней Учитель был непререкаемым авторитетом, едва ли не единственным носителем знания, необходимого ученику для будущей жизни. Получаемые знания гарантировали «успешность» Человека в обществе: трудоустройство, достойный уровень жизни.

Само обучение строилось по схеме традиционного комбинированного урока, в котором Учитель передавал материал, ученик его воспринимал, закреплял, а потом показывал учителю уровень усвоенного знания и развитых умений и навыков. Для получения крепких знаний ученики взаимодействовали не только с учителем, но и друг с другом, хотя сама классно-урочная система такого взаимодействия, как правило, не предусматривает. Однако сегодня технологии разрушают эту образовательную традицию.

Информационные ресурсы (а не просто Википедия) заменяют учителя по множеству вопросов, ученики «гуглят», а образовательное общение представляет собой пересылку материалов и ссылок на ресурсы. Пропадает потребность в учителе, разрываются социально-образовательные связи реального мира, а на их место приходят виртуальная коммуникация. В результате меняются мотивы обучения (Зачем слушать новую лекцию, если преподаватель может выложить ее в Интернете? Зачем объяснения учителя на уроке, когда можно посмотреть его на видео-хостинге?). 
Как следствие, традиционная индустриальная схема комбинированного урока перестает работать. Дегуманизация процесса образования проявляется в том, что Человек, получив доступ к огромному неиссякаемому объему знаний, перестает быть творцом собственного внутреннего мира знаний, представлений, концепций и систем. А ведь творчество в широком смысле этого слова - это призвание человека, и гуманистическая цель образования заключается в том, чтобы привести Личность к этой цели. Делают ли это современные образовательные технологии? Помогают ли они в становлении творческого Человека?

С воспитательной стороны информационные технологии также разрушают традиционные подходы и гуманистические ценности. У учителя (классного руководителя) появился серьезный конкурент - Интернет с его развлекательными и коммуникационными ресурсами. Это проявляется прежде всего в том, что детей сложно мотивировать (построить можно всегда), заинтересовать, увлечь, вывести в «офлайн», творчески зажечь и повести за собой, быть для них авторитетом. Кто помогает ученику ответить на фундаментальные вопросы собственного бытия: «с кем быть?», «кем быть?», «зачем быть?», «каким быть?», «как быть?» - классный руководитель, авторитетный учитель, родители, сверстники, СМИ, Интернет? Вопрос остается открытым.

В настоящее время традиционные воспитательные формы перестают эффективно работать, они нуждаются в «осовременивании», в умелом соединении виртуального и реального миров. Учителю важно не только быть «на связи» с учениками посредством социальных сетей, мессенджеров, не только использовать Интернет как помощника в коммуникации, но и применять эти средства для решения гуманистических педагогических задач и вопросов (они даны выше).

Теперь обратим внимание на признаки новой информационно-цифровой системы образования.

\section{1. Информационный шум.}

Впервые за всю историю Человечества информации вокруг Человека стало слишком много. Если раныше Homo sapiens с трудом должен был добывать постоянно недостающие сведения, то теперь для эффективной учебы и работы сведений вполне хватает, а для творческой деятельности зачастую нам необходимо оградить себя от «информационного шума». Это должно изменить подходы к передаче информации в системе образования, которая пока работает по традиционной системе передачи знаний.

\section{2. Цифровизация.}

Образовательный контент (содержание образования) все больше дается на электронных носителях, но более всего изменения касаются методов и форм его изучения. Теперь это не просто электронные источники информации типа Википедии, это целые образовательные порталы и онлайн-тренажеры, ведущие вас по этапам обучения, а в будущем это будут интерактивные электронные учебники и даже электронные роботы, использующие технологии дополненной реальности.

\section{3. Виртуализация.}

Содержание образования, формы его получения, а также коммуникация субъектов педагогического процесса переходят в виртуальное пространство. Электронные книги заменяют традиционные, переписка в мессенджерах - принятое общение глаза в глаза, 
работа с экраном монитора - ручку и бумагу. Такое взаимодействие через виртуальное пространство «покоряет» и систему образования: электронные дневники, задания через Интернет, дистанционное общение и т. д. Пока еще виртуальный мир дополняет реальный, но они уже смешиваются, а границы между ними стираются. «Захват» виртуальным пространством реальности очень похож на «захват», который сделала культура человечества с окружающей нас природой.

\section{4. Геймификация.}

Сегодня в процесс образования активно включаются «развлекательные» формы обучения, которые позволяют искусственно сделать его более интересным, увлекательным, разнообразным. Нужно отметить, что для гуманистической педагогики игры - это отличное дополнение к процессу обучения. Однако сейчас они претендуют на то, чтобы стать основной массовой формой обучения, дающей базовые (необходимые, но не очень высокие) результаты. Известно, что игра как форма деятельности должна привести Человека к учению, а учение - к творчеству. В случае с геймификацией виртуальная игра (даже образовательная) чаще уводит от творческой деятельности, поскольку является запрограммированной, ведущей Человека по алгоритмам, по задуманным лабиринтам, этапам разработчиков. Если игра не приводит к учебе и творчеству, если не формирует автономию, умение ставить цели и самостоятельно их достигать, то такое образование можно с уверенностью назвать «полуобразованием».

\section{5. Мобилизация.}

Не секрет, что мир вокруг нас становится мобильным, что зачастую требует мобильности от нас самих. В жизни в целом и в образовании в частности это проявляется умении решать несколько задач одновременно, быстро переключаться с одного вида деятельности на другой, быть всегда в информационном потоке. С другой стороны, такая организация жизнедеятельности формирует клиповое мышление, приводит к неумению глубоко погружаться в задачи и проблемы, отсутствию усидчивости и терпения.

Мы провели опрос учителей Саранска (на данный момент опрошено 160 человек, опрос продолжается), который посвящен проблеме влияния информационных технологий на педагогический процесс. Вот какие результаты мы получили.

Абсолютное большинство учителей независимо от стажа работы считают, что информационные технологии помогают учить и учиться. В то же время учителя отмечают, что детям стало сложнее учиться, а учителям сложнее учить, чем 10 лет назад. При этом наиболее значимым компонентом в процессе обучения (а значит, целью и мотивом) учителя считают заботу о детях и развитие их потенциала. Этот же компонент, по их мнению, является ведущей задачей и для администрации школ. Среди внешних факторов, которые мешают процессу обучения, лидирующие позиции занимают постоянный внешний контроль и социальное положение учителя. Материальное же положение как негативный фактор стоит только на 3-м месте.

Собранные данные отчетливо говорят нам о том, что все учителя выступают за использование современных информационных технологий. Однако очевидно, когда технологии становятся для нас самоцелью, они разрушают гуманистическую традицию нашего образования, «убивают» человеческое в отношениях между учителем и учеником, 
учителем и администрацией, учителем и родителями. Именно это стараются сохранить учителя в современных технократических условиях цифровизации. Мы столкнулись с противоречием: информационные технологии, которые призваны оптимизировать и облегчить процесс обучения, используются таким образом, что учиться и преподавать стало сложнее. Технологии, которые могут сделать педагогический процесс человечнее, на самом деле дегуманизируют его. И в этом нет вины технологий, причина - неправильное их использование, потеря по-настоящему человеческих целей и нивелирование истинных ценностей образования.

Итак, мы видим, что новые информационно-цифровая система образования с новыми технологиями «уничтожает» традиции обучения и воспитания и одновременно способствует нивелированию гуманистических ценностей. В практике образования это проявляется в следующем.

1. Образование все меньше становится свободным правом и все больше представляет собой социальную (даже техническую) обязанность. Это выражается в постоянном контроле всех участников данного процесса: учеников (от посещения школы до выполнения всех заданий и тестов), учителей (от использования методик до ведения документации) и администрации (от проверок учеников и учителей до отчетов перед министерствами).

2. Цифровые технологии (впрочем, как любые технологии) возводят второстепенные вопросы образования («как?») в разряд наиболее важных, а существенные с точки зрения гуманизма проблемы («зачем?» и «что?») отводят на второй план. Так, с технологической точки зрения в образовании значимыми являются решения следующих вопросов: способы достижения результатов (не с мотивационной и смысловой, а с формальной точки зрения), четкий контроль (учебы, времени, пространства, методов и форм), выставление предельно объективных баллов, организация внешних видимых условий обучения (технические средства, классные комнаты, финансирование и т. д.).

3. Технологии приводят к стандартизации. Это проявляется не столько в принимаемых стандартах, сколько в том, что они (стандарты) исходят из понятия внешней формальной нормы, а субъективные желания, ощущения, мысли ученика, его возможности не принимаются в расчет. Так, индивидуализация обучения заменяется стандартизацией. Норма в свою очередь определяет уровень успешности и неуспешности ученика, учителя, учебного заведения по внешним формальным критериям. Так, ученики делятся на лучших и худших не только от собственных успехов и неудач, сколько от умения адаптироваться, приспособиться к формально-нормативным требованиям системы.

4. Технологии требуют максимального образовательного результата (принцип максимальности). Они «хотят» использовать возможности Человека «на $110 \%$ », однако в условиях максимальных требований любая система начинает «расшатываться» и, теряя устойчивость, в конечном итоге распадается на части.

5. Технологии призывают нас обращать внимание на внешние формальные признаки и игнорировать внутренне глубинные процессы. Выполнение задания, ведение документации, участие в олимпиаде, посещение мастер-классов и т. д. - для технологизма это истинные критерии эффективности работы. Тогда как для гуманизма это всего 
лишь средства реализации человеческого потенциала. Гуманистически настроенный учитель не будет проводить олимпиаду, классный час или иное мероприятие, если у учеников не сформированы правильные мотивы участия в них.

6. Для технологизма образование - это сфера услуг, а для гуманизма - это сфера человеческих отношений. В технологической образовательной парадигме учитель это «трудовая единица». С цифровизацией образования эта единица становится буквальной, отводя человеческий фактор на второй план. Он уступает место таким вопросам, как рейтинг ученика, учителя, учебного заведения, статистика, финансирование, отчетность и т. д. Для гуманизма главное - это отношения (ученика к учебе, учителя к ученику, директора к учителю и т. д.) и, как результат, эффективность обучения.

7. Цифровые технологии поощряют образовательную гонку и конкуренцию. Классно-урочная система всегда предполагала конкуренцию детей в классе, классов в школе, школ в городе или районе. С технологической точки зрения все должны принимать участие в «образовательной гонке», и лишь только лучшие получат свой «приз». До цифровизации такая конкуренция была ограниченной, поскольку отсутствовали необходимые информационные ресурсы и система передачи данных. Сейчас мы живем в мире глобальной конкуренции между людьми, организациями, народами и государствами, да еще капиталистический образ жизни породил и поддерживает конкуренцию в сфере образования (между учениками, учителями, учебными заведениями, региональными системами) [5].

Цифровизация сделала возможной образовательную конкуренцию в режиме онлайн по всей стране, она может буквально визуализировать ее. Как вам идея единого образовательного портала, на котором вы можете посмотреть видеоурок по истории древнего мира, проведенный разными учителями в любой школе страны, и сравнить, чей урок лучше, да еще поставить при этом «лайк» и написать комментарий? В США такая система уже тестируется. Гуманизм призывает нас к сотрудничеству, исходя из того, что конкуренция и так является объективно присутствующим атрибутом в жизни.

Отказ от использования технологий невозможен, как невозможно вернуться в детство. Самый главный вопрос: как осовременить традиционные подходы и гуманизировать процесс образования в новых условиях?

На наш взгляд, необходимо следовать правильной расстановке целей и ценностей. Такой подход можно назвать принципом «иерархического баланса».

Любая система работает эффективно не только при условии сбалансированности всех ее подсистем, но и при условии иерархического подчинения второстепенного главному, средства - цели, основания - ценностной вершине. С другой стороны, высшие ценности и цели всегда опираются на средства, как на свой фундамент, без которого их достижение невозможно [6]. Именно поэтому при постановке задач развития образования мы должны опираться на следующие подходы:

1. Части системы должны быть объединены не механически, а на смыслообразующей ценностной основе. Вспомним слова М. М. Бахтина: «елое называется механическим, если отдельные элементы его соединены только в пространстве и времени внешнею связью, а не проникнуты внутренним единством смысла. Части такого целого хотя и лежат 
рядом и соприкасаются друг с другом, но в себе они чужды друг другу» [7]. Единство смысла может быть достигнуто, если гуманистические ценности выступят интегрирующими целями воспитания и образования в условиях информационно-цифровой системы.

2. Гуманистические ценности и цели образования в новой цифровой эре остаются прежними - помощь Человеку в самосовершенствовании, в раскрытии творческого потенциала, в его реализации на благо людям, обществу, стране и миру, в продолжении социально-культурной традиции Человечества. Цифровые технологии являются средствами для реализации заявленных целей.

3. Если смыслы и цели образования будут органически объединены, они будут понятны всем участникам педагогического процесса: учителям, директорам школ, управленцам в сфере образования, ученикам и родителям. Сейчас мы наблюдаем разрывы в целях и смыслах. Например, сравните цель и смысл сдачи ЕГЭ.

4. В соответствии с едиными целями-смыслами мы должны изменить подход к системе управления образованием. Это не техническая система, а социально-гуманистическая (человеческая) система. И она требует другого управления, в основе которого лежат иные подходы, принципы, методы и формы. Если в механической системе главное - выполнение четких требований, контроль, стандартизация, конкуренция и одинаковость, то в системе образования - создание благоприятных условий, доверие (а потом контроль), индивидуализация, сотрудничество и разнообразие.

5. Не нужно опасаться развития информационно-цифровой образовательной системы, которая усиливает свое технологическое влияние на все сферы жизни Человечества. Все мы в жизни, в воспитании и образовании должны «бороться» не только за сохранение, но и укрепление гуманистических ценностей и человеческих смыслов и целей образовательного процесса.

\section{Список литературы}

1. Кадакин В. В., Шукшина Т. И., Замкин П. В. Электронные средства конструирования методического обеспечения современного урока // Научно-методический журнал «Гуманитарные науки и образование». 2017. № 1. C. 32-35. URL: https:// www.mordgpi.ru/upload/iblock/caa/1_29_-_yanvar_mart_pdf (дата обращения: 18.11.2019).

2. Куриљей Р. Как технология изменит нас: [лекция]. URL: https://ideanomics.ru/ lectures/15954 (дата обращения: 18.11.2019).

3. Apхипова C. В., Чаприна А. С. Информационная компетентность педагога-дефектолога // Научно-методический журнал «Гуманитарные науки и образование». 2019. № 2. С. 7-14. URL: https://www.mordgpi.ru/upload/iblock/291/GNIO-_-2_38_-2019.pdf (дата обращения: 18.11.2019).

4. Робинсон К., Ароника Л. Школа будущего. Как вырастить талантливого ребенка. М.: Манн, Иванов и Фербер, 2016.

5. Богуславский М. В., Неборский Е. В. Стратегические тенденции развития системы высшего образования в Российской Федерации // Гуманитарные исследования Центральной России. 2017. № 2. С. 7-20. 
6. Высшее образование в немецкой и русской традициях: колл. моногр. / М. В. Богуславский, Е. В. Неборский, В. В. Неборская [и др.]. Ижевск: Ин-т компьютерных исследований, 2016. 272 с.

7. Бахтин М. М. Эстетика словесного творчества / сост. С. Г. Бочаров, примеч. С. С. Аверинцев и С. Г. Бочаров. М.: Искусство, 1979. 423 с. URL: http://teatr-lib.ru/ Library/Bahtin/esthetic/\#_Toc225599031 (дата обращения: 18.11.2019).

\section{References}

1. Kadakin V. V., Shukshina T. I., Zamkin P. V. Elektronnye sredstva konstruirovaniya metodicheskogo obespecheniya sovremennogo uroka. Nauchno-metodicheskiy zhurnal "Gumanitarnye nauki i obrazovanie". 2017, No. 1, pp. 32-35. Available at: https://www. mordgpi.ru/upload/iblock/caa/1_29_-_yanvar_mart_pdf (accessed: 18.11.2019).

2. Kurzweil R. Kak tekhnologiya izmenit nas. Available at: https://ideanomics.ru/lectures/15954 (accessed: 18.11.2019). (in Russian)

3. Arkhipova S. V., Chaprina A. S. Informatsionnaya kompetentnost pedagoga-defektologa. Nauchno-metodicheskiy zhurnal "Gumanitarnye nauki i obrazovanie". 2019, No. 2, pp. 7-14. Available at: https://www.mordgpi.ru/upload/iblock/291/GNIO__-2-_38_2019.pdf (accessed: 18.11.2019).

4. Robinson K., Aronika L. Shkola budushchego. Kak vyrastit talantlivogo rebenka. Moscow: Mann, Ivanov i Ferber, 2016. (in Russian)

5. Boguslavskiy M. V., Neborskiy E. V. Strategicheskie tendentsii razvitiya sistemy vysshego obrazovaniya v Rossiyskoy Federatsii. Gumanitarnye issledovaniya Tsentralnoy Rossii. 2017, No. 2, pp. 7-20.

6. Boguslavskiy M. V., Neborskiy E. V., Neborskaya V. V. et al. Vysshee obrazovanie v nemetskoy i russkoy traditsiyakh: koll. monogr. Izhevsk: In-t kompyuternykh issledovaniy, 2016. $272 \mathrm{p}$.

7. Bakhtin M. M. Estetika slovesnogo tvorchestva. Moscow: Iskusstvo, 1979. 423 p. Available at: http://teatr-lib.ru/Library/Bahtin/esthetic/\#_Toc225599031 (accessed: 18.11.2019). (in Russian)

\section{Интернет-журнал \\ «Проблемы современного образования» \\ 2020, № 3}

Статья поступила в редакцию 09.12.2019

The article was received on 09.12.2019 